\title{
Critical Limb Ischemia: Definition and Natural History
}

\author{
S. Novo*, G. Coppola and G. Milio \\ Chair of Cardiovascular Disease, University of Palermo, Italy
}

\begin{abstract}
The term critical limb ischemia refers to a condition characterized by chronic ischemic at-rest pain, ulcers, or gangrene in one or both legs attributable to objectively proven arterial occlusive disease. Critical limb ischemia implies chronicity and is to be distinguished from acute limb ischemia. Its incidence is approximately 500 to 1000 per million year, with the highest rates among older subjects, smokers and diabetics. The rate of primary amputation ranges from $10 \%$ to $40 \%$, and was performed only when no graftable distal vessels were present, or in neurologically impaired or hopelessly nonambulatory patients. Contrarily, in some highly specialized and aggressive centres about $90 \%$ of patients with CLI had an attempted revascularization. Furthermore, patients with critical limb ischemia have an elevated risk of future myocardial infarction, stroke and vascular death, 3-fold higher than patients with intermittent claudication. Therefore, due to its negative impact on the quality of life and the poor prognosis both in terms of limb salvage and survival, critical limb ischemia is a critical public health issue.
\end{abstract}

Keywords: Peripheral arterial disease, critical limb ischemia, arterial occlusive disease,Fontaine's classification, cardiovascular morbidity, cardiovascular mortality, risk factors, amputation, surgical revascularization.

\section{INTRODUCTION}

Peripheral arterial disease (PAD) of the lower limbs is the third most important site of atherosclerotic disease alongside coronary heart disease (CHD) and cerebrovascular disease (CVD). This clinical condition has often been neglected in the past but, in the recent years, PAD has received growing attention as an important cause of disability and of cardiovascular morbidity and mortality [1].

Critical limb ischemia (CLI) is the term used to delineate the condition in which arterial disease has resulted in pain in the foot even at the rest or in a breakdown of the skin (ulcer or gangrene); it therefore coincides with stages III and IV of Fontaine's classification (Table 1), which defines respectively the ischemic rest pain without skin lesions and the presence of ulcers or gangrene (Fig. 1) [2, 3]. CLI implies chronicity, because it is the progressive evolution of PAD, and is to be distinguished from acute limb ischemia, which is always consequent to arterial thrombosis or peripheral thromboembolism. If not revascularized, patients with CLI are at risk for limb loss and for potentially fatal complications because of the progression of gangrene and the development of sepsis; the best patient outcome is achieved when the diagnosis and appropriate treatment for CLI are not delayed [2]. Furthermore, patients with CLI are at greater cardiovascular risk than those with intermittent claudication [4].

Simple non-invasive tests, such as measurement of ankle/brachial pressure index, ankle and toe Doppler pressures, as well as the detection of transcutaneous $\mathrm{PO}_{2}$ and $\mathrm{PCO}_{2}$ take only a few minutes to provide sufficient information to confirm the diagnosis of PAD and to document the severity of limb ischemia [2]. There are conflicting positions about the value of toe pressure measurement. Kroger et al. stated that toe pressure

*Address correspondence to this author at the Chair of Cardiovascular Disease, University of Palermo, Italy; E-mail: novosav@unipa.it measurement is more useful to exclude CLI than to prove it [5], while Zwicky et al. demonstrated that toe pressure measurement represents the most reliable test to confirm diagnosis and to disclose a possible improvement of perfusion in CLI patients [6].

Diagnostic imaging studies, such as ultrasound duplex scanning, magnetic resonance angiography (MRA) or traditional arteriography, provide detailed information to plan revascularization [2]. In patients requiring an assessment of the peripheral vascular bed before distal revascularization, contrast enhanced MRA can be the first examination and only in the case of inadequate results selective arteriography needs to be performed [7]. This is confirmed by a recent meta-analysis in 1090 patients, showing that in PAD patients, MRA is highly accurate for the assessment of the lower extremity arterial bed; threedimensional Gd-enhanced MRA, especially, improves diagnostic performance compared with 2D MRA (relative diagnostic odds ratio 2.8 [95\% confidence interval 1.2-6.4]) [8].

Balloon angioplasty and stenting work best for focal segments of narrowing or short occlusions of the iliac arteries, but endovascular treatments yield progressively poorer results with longer and more distal lesions. Long segments of occlusion, especially those distal to the common femoral artery, are best treated with surgical bypass [2]. Recently, however, several reports indicate percutaneous transluminal angioplasty or more complex endovascular procedures, such as excimer laser recanalization followed by balloons angioplasty, may be useful for treating arteries below the knee [9-11]. Furthermore, arterial homograph transplantation has been shown to be useful for limb salvage in CLI [12].

Pharmacotherapy $[13,14]$, topical therapies and hyperbaric oxygen treatment $[2,14]$, may have a role for patients in whom revascularization procedures have failed or for those in whom revascularization is not technically possible, particularly when amputation is the only 
Table 1. Leriche-Fontaine Classification

\begin{tabular}{|c|c|c|c|}
\hline STAGES & SIMPTOMS & PATHOPHYSIOLOGY & PATHOPHYSIOLOGICAL CLASSIFICATION \\
\hline STAGE I & Asymptomatic or effort pain & Relative Hypoxia & Silent Arteriopathy \\
\hline STAGE II A & $\begin{array}{c}\text { Effort pain } \\
\text { Pain free walking distance }>200 \mathrm{mt}\end{array}$ & Relative Hypoxia & $\begin{array}{l}\text { Stabilized Arteriopathy } \\
\text { Non Invalidant Claudicatio }\end{array}$ \\
\hline STADIO II B & Pain free walking distance $<200 \mathrm{mt}$ & Relative Hypoxia & $\begin{array}{l}\text { Instable Arteriopathy } \\
\text { Invalidant Claudicatio }\end{array}$ \\
\hline STAGE III A & $\begin{array}{l}\text { Rest Pain } \\
\text { Ankle arterial pressure }>50 \mathrm{~mm} \mathrm{Hg}\end{array}$ & $\begin{array}{l}\text { Cutaneous Hypoxia } \\
\text { Tissue Acidosis } \\
\text { Ischemic Neuritis }\end{array}$ & $\begin{array}{l}\text { Instable Arteriopathy } \\
\text { Invalidant Claudicatio }\end{array}$ \\
\hline STAGE III B & $\begin{array}{l}\text { Rest Pain } \\
\text { Ankle arterial pressure }<50 \mathrm{~mm} \mathrm{Hg}\end{array}$ & $\begin{array}{l}\text { Cutaneous Hypoxia } \\
\text { Tissue Acidosis } \\
\text { Ischemic Neuritis }\end{array}$ & $\begin{array}{l}\text { Instable Arteriopathy } \\
\text { Invalidant Claudicatio }\end{array}$ \\
\hline STAGE IV & $\begin{array}{l}\text { Trophic lesions } \\
\text { Necrosis or Gangrene }\end{array}$ & $\begin{array}{c}\text { Cutaneous Hypoxia } \\
\text { Tissue Acidosis } \\
\text { Necrosis }\end{array}$ & Evolutive Arteriopathy \\
\hline
\end{tabular}

alternative. In these cases, prostanoids are the best-studied class of drugs and they are widely used in Europe [15].

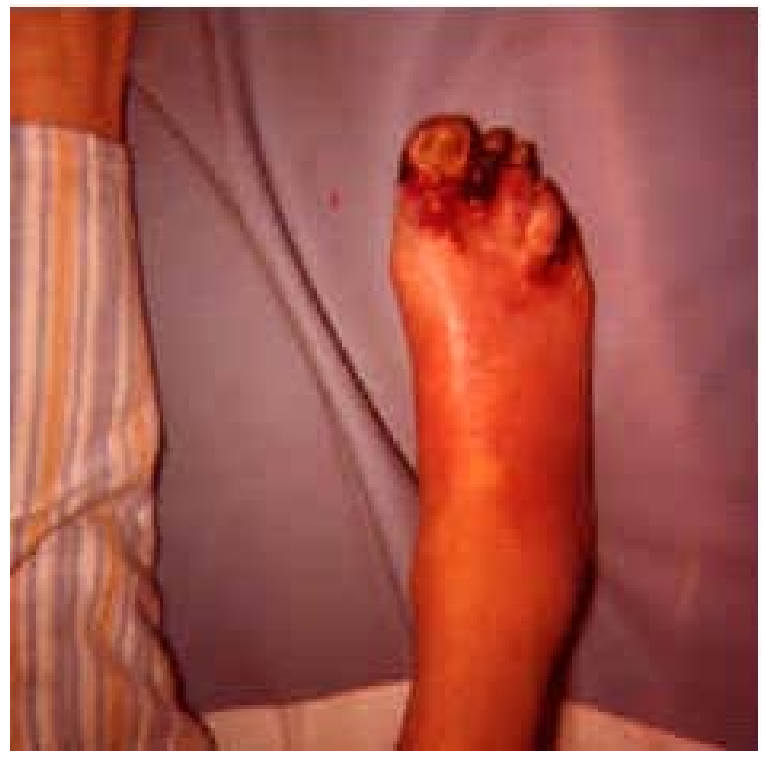

Fig. (1). Patient suffering from Critical Limb Ischaemia: gangrene of $2^{\text {nd }}$ and $5^{\text {th }}$ toe.

Although other medical approaches, such as the use of other vasoactive drugs, haemorheological agents or geneinduced angiogenesis may be useful to improve walking distance in patients with intermittent claudication, their effectiveness in the treatment of patients with CLI has yet to be demonstrated [16]. However, recent data using intramuscular vascular endothelial growth factor (VEGF) gene therapy indicate that, in CLI patients, this therapeutic approach is feasible, safe and effective [17]. Other therapies include spinal cord stimulation [18, 19], chemical lumbar sympathectomy [20] and intermittent pneumatic compression [21], the results of which are controversial.

\section{DEFINITION OF CLI}

"Critical" according to the Oxford dictionary means: a "turning point" where an acute change for better or worse may be anticipated. Critical ischemia can be defined as the level of reduction in limb blood flow that threatens the viability of part of, or the entire limb. The answer to the question "How critical is critical leg ischemia?", a few years ago, could have been: "We don't know!" [22]. In fact, Fontaine's original classification was based on clinical information, stage III being defined by ischemic rest pain without skin lesions and stage IV by the presence of ulcers or gangrene [23].

The need for a more objective definition of Fontaine's stages III and IV became evident when it was shown that these patients have a very high risk of cardiovascular events, amputation, and mortality, so that the lack of uniform criteria in reporting the results of studies on CLI precluded the acquisition of reliable data and prevented the comparison of efficacy of different therapeutic strategies. Thus, to clarify, to specify, and to homogenize the definition of PAD stages III and IV, European vascular specialists prepared a Consensus Document [24]. In the document, CLI, in both diabetic and non diabetic patients, was defined by either of two criteria: 1) persistent, recurrent, distal extremity pain at rest requiring that the patient uses analgesics for more than 2 weeks, with an ankle systolic pressure of equal to or lower than $50 \mathrm{~mm} \mathrm{Hg}$ and/or a toe systolic pressure equal to or lower than $30 \mathrm{~mm} \mathrm{Hg}$, or 2) ulceration or gangrene of the foot or toes in combination with the hemodynamic criteria listed above. Furthermore, variables describing the compromised microcirculation (such as a transcutaneous $\mathrm{PO}_{2}$ equal to or lower than $30 \mathrm{~mm} \mathrm{Hg}$ ) were included, particularly to be applied in patients with unreliable pressure readings.

The Second European Consensus Document induced a general agreement in the scientific community; however, the following criticisms were raised: 1) the panel of experts consisted entirely of Europeans, 2) there was no distinction between acute limb ischemia and chronic critical limb ischemia, and 3) arterial pressure lower than $50 \mathrm{~mm} \mathrm{Hg}$ at the ankle and lower than $30 \mathrm{~mm} \mathrm{Hg}$ at the toe, and transcutaneous $\mathrm{PO}_{2}$ lower than $30 \mathrm{~mm} \mathrm{Hg}$ were considered too low. So the TransAtlantic InterSociety Consensus [2] on management of PAD reviewed the definition of CLI and the 
current recommendation is that the term CLI be based solely on clinical presentation of the patient and the evidence that chronic ischemic rest pain (Fontaine's stage III), or the presence of ulcers, or gangrene (Fontaine stage IV) are predominantly due to PAD. The evidence for PAD could equally well come from an ankle pressure lower than 50-70 $\mathrm{mmHg}$, or a toe pressure lower than $30-50 \mathrm{mmHg}$, or transcutaneous $\mathrm{PO}_{2}$ lower than $30-50 \mathrm{mmHg}$.

\section{EPIDEMIOLOGY AND RISK FACTORS}

The true incidence of CLI is not known because there are no registries. From a national survey by the Vascular Surgery Society of Great Britain and Ireland emerged an annual incidence of 400 per million per year [25]. The incidence of CLI can also be extrapolated from the better documented prevalence of intermittent claudication. Assuming that the overall prevalence of intermittent claudication is $3 \%$ and that $5 \%$ of effected individuals will develop CLI over 5 years, this gives an incidence of CLI of 300 per million per year. However, by this method the true incidence of CLI is likely underestimated because not all patients with CLI have experienced symptoms of previous claudication. In a Finnish study [26], 39\% of patients presenting with CLI had never experienced claudication. Of these $54 \%$ were diabetic and $89 \%$ had ulcers as the initial feature of CLI. Finally, if calculated from the number of major amputations performed, the CLI incidence is approximately 500 to 1000 per million per year, assuming that $80 \%$ of major amputations are performed for ischemia and that only $25 \%$ of patients with CLI require major amputation [2].

The most important risk factors for the developments of CLI are age, smoking and diabetes mellitus. A Danish national discharge survey showed that in 1980 the incidence of lower limb major amputations increased from 0.3 per 100,000 per year in those younger than 40 years, to 226 per 100,000 per year in these older than 80 years [27]. Similarly, diabetic patients are approximately 10 times more likely to need a major amputation than nondiabetic PAD patients [28]. Smoking seems to have an additive effect and, in any case, major amputation is more frequent among PAD who are heavy smokers [29], independently from the presence of diabetes.

\section{THE HISTORY AND CLINICAL EVALUATION OF CLI}

Critical limb ischemia is dominated by a severe, often intolerable, pain caused by ischemia, areas of tissue loss, ischemic neuropathy or a combination of these. Ischemic rest pain typically occurs at night with attacks lasting minutes to hours and is localized in the distal part of the foot or in the vicinity of an ischemic ulcer or gangrenous toe. Not infrequently, pain precedes the formation of an ischemic ulcer or gangrene and contracture of the knee and ankle joints may occur. Often, pain is relieved by large doses of strong analgesics or opiates [2, 3].

A diagnosis of CLI can be made from the patient's history and physical examination, but further diagnostic studies are usually needed for clinical decision making (Table 2). Ankle and toe pressure should be measured in all patients and can be helpful; basic hematologic and biochemical tests should be performed (Table 3 ).

Table 2. Purpose of Investigations for Critical Limb Ischemia

\begin{tabular}{|c|c|}
\hline 1) & $\begin{array}{c}\text { Confirm the diagnosis, localize the responsible arterial lesions } \\
\text { and grade their severity; }\end{array}$ \\
\hline 2) & $\begin{array}{l}\text { Assess the need for intervention, operative risk and operative } \\
\text { strategy; }\end{array}$ \\
\hline 3) & Certain basic investigations. \\
\hline 4) & Verify the involvement of other systems with atherosclerosis. \\
\hline
\end{tabular}

Simple non-invasive tests like transcutaneous oxygen measurements $\left(\mathrm{TCPO}_{2}\right)$ are used to measure oxygen tension in the cutaneous blood flow, metabolic activity, oxyhemoglobin dissociation and oxygen perfusion through the tissue; in contrast to capillary microscopy, its value in estimating nutritive perfusion is limited because it is an indirect measure of skin perfusion and is not necessarily derived from capillaries alone [2]. Laser Doppler flowmeter and radionuclide perfusion scans may be helpful to complete microcirculatory investigations.

Angiography, color duplex imaging and magnetic resonance imaging (MRI) are the current options to find and define an arterial lesion and to identify patients for surgical or non-surgical intervention [2]. Color duplex imaging has been proposed as an alternative to angiography; it has less disadvantages, it is completely safe and much less expensive and in expert hands can provide most of the essential anatomic information plus some functional information (for example, velocity gradients across stenoses). Nevertheless, full angiography, with visualization from the infrarenal aorta to the pedal arteries using digital subtraction angiography (DSA) techniques, remains the procedure of choice in most cases. Thus, if a patient qualifies for invasive treatment, angiography will be required in almost all elective cases, preoperatively for surgical reconstruction and before or during catheter-based interventions. Color duplex scanning is used selectively mainly to characterize specific lesions with regard to their suitability for endovascular treatment [2].

Table 3. Basic Hematologic and Biochemical Tests

\begin{tabular}{|c|c|}
\hline 1$)$ & Complete blood count; \\
\hline 2$)$ & Platelet count; \\
\hline 3$)$ & Blood glucose or haemoglobin A1c; \\
\hline 4$)$ & Urea, creatinine and lipid profile; \\
\hline 5$)$ & $\begin{array}{c}\text { Erythrocyte sedimentation rate, hypercoagulability screen and } \\
\text { homocysteine levels in special categories of patients. }\end{array}$ \\
\hline
\end{tabular}

Lastly, MRA techniques are adequate for stenosis qualification and discriminating between high grade stenoses and complete occlusion. In some cases MRA, especially with contrast enhancement, may be as good as conventional angiography. Recently, a meta-analysis of 1090 patients with PAD [7] showed a new scenario in which Gd-enhanced MRA may become the preferred imaging technique and the first examination in patients requiring assessment of the 
peripheral vascular bed before distal revascularization; selective arteriography could be performed only in the case of inconclusive results.

\section{THE FATE OF THE AFFECTED LIMB}

It is practically impossible to describe the natural history of CLI in terms of the fate of the ischemic limb, because most patients not requiring primary amputation undergo some form of arterial reopening procedure.

The rate of primary amputation ranges from $10 \%$ to $40 \%$, and was performed only when no graftable distal vessels were present, or in neurologically impaired or hopelessly nonambulatory patients [2]. Differently, in some highly specialized and "aggressive" centres revasculation was attempted in about $90 \%$ of the patients with CLI [30, 31]. For the subgroup of patients non candidates for arterial reopening procedures and those in whom these procedures have failed, results at 6 months show that approximately $40 \%$ will lose their leg $[32,33]$.

In patients with disabling claudication or critical limb ischemia, revascularization procedures are highly effective. In particular, for high-grade stenoses or short arterial occlusions, percutaneous transluminal angioplasty (PTA) should be the first choice method followed by the best surgical procedure later on [34].

As endovascular techniques have the advantage of a lower morbidity and mortality risk compared with open surgical revascularizations; PTA is generally applied to more focal diseases of the distal abdominal aorta, common iliac arteries and external iliac arteries. For diffuse, extensive, complex, multilevel, multifocal or totally occluded atherosclerotic segments of the infrarenal abdominal aorta and iliac arteries, the procedure of choice is surgery [2]. During the past 10 years, stents have played an important role in improving long-term PTA results by preventing recoil, PTA-related flow-limiting dissection and chronic iliac artery occlusion. Moreover, intravascular ultrasound scanning provides an accurate measurement of the diameter of the diseased arteries and can be used to evaluate plaque morphology and provide structural information assessing the adequacy of stent deployment. Thus, PTA procedures with primary stenting extend the indication for more diffuse, multilevel, complex, or totally occluded atherosclerotic segments. Combined surgical and endovascular procedures are increasingly being used for the common occurrence of multilevel disease in patients with critical limb ischemia. Intimal hyperplasia is thought to be the most important cause of in-stent restenosis following stent deployment. An increase in cell number in the inner intima and accumulation of matrix around stents have been observed in resected arterial specimens with instent lesions, which could be prevented by radiation therapy or sirolimus-eluting stents in the very near future [35].

It is controversial whether an aggressive revascularization policy improves the outcome of CLI. Tunis et al. [36] reported that, in the United States, the increased use of interventional procedures from 1979 through 1989 (angioplasty, including stenting implant, increased from 1 to 24 per 100, 000, and bypass surgery from 32 to 65 per 100 , 000 ) did not reduce the rate of amputation (from 28 to 32 per 100, 000). Conversely, a Swedish study [37] revealed that, over a period of 8 years, a decrease in primary amputations (from $42 \%$ to $27 \%$ ), associated with a corresponding increase in revascularizations, resulted in a overall decrease in amputations from $61 \%$ to $47 \%$.

Recently many studies have reviewed the current role and results of angioplasty in the management of critical limb ischaemia and the results of these studies justify the continuing use of PTA as first-line treatment for critical limb ischemia, in which time can be important for outcome with respect to limb salvage $[38,39]$. Vascular surgery had a positive effect on the major amputation rate also in Denmark [40] and in Western Finland [41]. However, a Scottish study [42] highlighted inconsistencies within different age groups. Actually, between 1981 and 1990, in the population younger than 65 years, the major amputation rate decreased by $45 \%$ while in these older than 65 years, it increased by $54 \%$ [42].

Interestingly, increased preoperative levels of $\mathrm{C}$ reactive protein predict postoperative amputation of the femoropopliteal by-pass surgery for CLI [43]. Also ankle pressure is predictive of the fate of the ischemic limb in CLI. The Joint Vascular Group in Britain [44] found that there were significantly $(\mathrm{p}<0.01)$ more viable legs at 1 year among those patients with CLI who had rest pain (Fontaine's stage III) and an ankle pressure greater than $40 \mathrm{mmHg}$ compared with those with rest pain and an ankle pressure less than 40 $\mathrm{mmHg}$. This differentiation, however, was lost in those patients with ulceration or gangrene (Fontaine's stage IV).

With respect to the level of amputation, it is generally believed that increasing the proportion of below-knee to above-knee amputations must inevitably lead to a higher failure rate, although, to the best of our knowledge, no study has compared directly the outcome of the two procedures. Data on below knee amputations indicate that the reamputation rate ranges from $4 \%$ to approximately $50 \%$, with the highest rate in amputees whose wounds do not heel primarily $[45,46]$. In this regard, it is interesting to note the finding of a European study showing that surgeons' assessment of the likelihood of healing was wrong in $21 \%$ of cases in which the healing was considered to occur, and in $52 \%$ of cases in which the surgeon believed that healing would not occur [47].

Finally, it has been reported that $15 \%$ of amputees require contralateral amputation over a 2-year period [48]. Although the need for major amputation was related to the absence of distal pulses, $10 \%$ of the amputees with palpable contralateral foot pulses lost also that foot within 2 years.

In patients for whom revascularization is not possible, or else it fails, an alternative is to try to modify the consequences of the low perfusion pressure on the distal microcirculation by some form of pharmacotherapy to reverse the rest pain and avoid amputation [2, 14]. Prostanoids have been shown to have beneficial effects on most of the microcirculatory components by preventing the reciprocal potentiation of platelet activation, leukocyte activation and the damaged vascular endothelium; this is the reason why prostanoids have, in the last few years, been the most widely tested group of drugs in this condition [2, 15, $49,50,51]$. Good results were achieved with Alprostadil in the ICAI study [15], and with Iloprost, as demonstrated in a meta-analysis by Loosemore and Dormandy [49]. Recently, interesting results were obtained with intermittent infusion 
of Iloprost [50], as well as of Alprostadil in the ORACLE Study [51], with a good cost/efficacy ratio.

Smoking cessation, treatment of hypertension, diabetes and hyperlipidemia are the milestones for the control of risk factors and reduction of the risk of cardiovascular events and mortality of these patients.

Patients with CLI need long-term treatment with antiplatelet agents to reduce progression of atherosclerosis, whereas the prevention of thrombosis in prosthetic femoropopliteal grafts is uncertain [2]. The Antiplatelet Trialists' Collaboration showed clear evidence that aspirin, ticlopidine and clopidogrel produce a $25 \%$ reduction of vascular events (stroke, myocardial infarction and vascular death) [52], and also improve patency of peripheral arteries and grafts [53]. However only the CAPRIE study has been conducted in patients with PAD with rest pain and ischemic ulcers [54].

About $20-30 \%$ of patients with CLI can not be treated by surgical or endovascular revascularization and the only option for them is often amputation. For this group of patients there is an urgent need for alternative treatment strategies and several strategies are currently being tested to stimulate collateral artery growth. Arteriogenesis is defined as growth of preexisting arteriolar connections into true collateral arteries [55]. Recent investigations have shown that intramuscular vascular endothelial growth factor (VEGF) gene therapy can expedite or augment collateral artery development in CLI patients; this therapeutic approach is feasible, safe and effective [2,20].

\section{CARDIOVASCULAR MORBIDITY AND MORTAL- ITY}

Due to the systemic nature of atherosclerosis, the coexistence of coronary and carotid artery disease is very common in PAD patients who, thus, are at high risk of myocardial infarction, stroke and vascular death $[56,57]$. An Italian multicenter prospective observational study [58] followed 574 patients with CLI. After a 3-month follow-up, 3 patients $(0.5 \%)$ had a myocardial infarction, $6(1 \%)$ a stroke, $70(12.2 \%)$ a major amputation, and $50(8.7 \%)$ died. After 2 years, the overall mortality was $31.6 \%$, with an incidence of vascular death markedly higher than that for non vascular death (34.5\% vs $8.5 \%$ ). In Britain, in unselected CLI patients, the 1 year mortality rate was found to be around 20\% [44], i.e. similar to that observed in Italy [58]. Conversely, in a Swiss study [59] a similar proportion died over 6 months. Another study [60] evaluated the outcome of PAD patients presenting with rest pain. The results showed that after 10 years of follow-up, only $13.7 \%$ were alive, the most frequent cause of death being myocardial infarction $(25 \%)$. The results of all these studies seem to indicate that survival rates in patients with CLI is markedly lower than that reported for patients with intermittent claudication. However, only one study [4] compared directly the prognosis in CLI with that in intermittent claudication. In an unselected population of 297 patients with symptomatic PAD, those with CLI had a 3-fold higher risk for all cause and cardiovascular mortality than patients with intermittent claudication. The survival rate at 3 years was $52.5 \%$ in patients with CLI and $85.5 \%$ in those with intermittent claudication. At the multivariate analysis the presence of CLI was a stronger predictor of mortality than a low ankle brachial index or a history of cardiovascular disease. All these data, and especially the finding that about $50 \%$ of all fatal cardiovascular events occur in patients without a history of ischemic coronary or cerebral disease [4], indicate a possible role of CLI as a harbinger of atherosclerosis progression.

Inflammatory stimuli secondary to severely defective tissue oxygenation and, if present, to ulcers and necrosis may concur to this process. Indeed, increased plasma levels of fibrinogen, an acute phase reactant, were found to be predictive of death in old patients with CLI [61].

\section{CONCLUSIONS}

With an incidence estimated at approximately 500 to 1000 per million per year, and a poor prognosis both in terms of limb salvage and survival, CLI is a critical public health issue. Over the last 2 decades, we have witnessed many important advances in vascular and endovascular procedures which provide a potentially better chance for limb salvage. Similarly, in recent years a number of studies suggest that antiplatelet drugs, simvastatin and the ACE inhibitor ramipril reduce cardiovascular morbidity and mortality in PAD [62-64]. There is need for prospective trials specifically aimed at assessing whether these pharmacological approaches reduce the cardiovascular risk in CLI.

\section{REFERENCES}

[1] Novo, S. The patients with intermittent claudication. Everyday problems in clinical cardiology. Excerpta Medica: Amsterdam, 1995, Vol. 5: $\mathrm{n}^{\circ} 7$.

[2] Management of peripheral arterial disease (PAD). TransAtlantic Inter-Society Consensus (TASC). J. Vasc. Surg., 2000, 31, S1S296.

[3] Novo, S. Classification, epidemiology, risk factors and natural history of peripheral artery disease. Diabetes, Obesity and Metabolism, 2002, 4 (Suppl. 2), S1-S6.

[4] Pasqualini, L.; Schillaci, G.; Vaudo, G.; Innocente, S.; Ciuffetti, G.; Mannarino, E. Predictors of overall and cardiovascular mortality in peripheral arterial disease. Am. J. Cardiol., 2001, 88, 1057-1060.

[5] Kroger, K.; Stewen, C.; Santosa, F.; Rudofsky, G. Toe pressure measurements compared to ankle artery pressure measurements. Angiology, 2003, 4 (Suppl. 1), S39-S44.

[6] Zwicky, S.; Mahler, F.; Baumgartner, I. Evaluation of clinical tests to assess perfusion in chronic critical limb ischemia. $V A S A, \mathbf{2 0 0 2}$, 31, 173-178.

[7] Brillet, P.Y.; Tassart, M.; Bazot, M.; Le Blanche, A.P.; Allaire, E.; Boudghene, F. Investigation of peripheral vascular bed in critical lower limb ischemia: comparative study between arteriography and magnetic resonance angiography. J. Mal. Vasc., 2001, 26, 3138.

[8] Koelemay, M.J.; Lijmar, J.G.; Stoker, J.; Legemate, D.A.; Bossuyt, P.M. Magnetic resonance angiography for the evaluation of lower extremity arterial disease: a meta-analysis. $J A M A, \mathbf{2 0 0 1}, 285$, 1338-1345.

[9] Brillu, C.; Picquet, J.; Villapadierna, F.; Papon, K.; L’Hoste, P.; Jousset, Y.; Enon, B. Percutaneous transluminal angioplasty for management of critical ischemia in arteries below the knee. Ann. Vasc. Surg., 2001, 15, 75-81.

[10] Jamsen, T.S.; Manninen, H.I.; Jaakkola, P.A.; Matsi, P.J. Longterm outcome of patients with claudication after balloon angioplasty of the femoro-popliteal arteries. Radiology, 2002, 225, $345-352$. 
[11] Gray, B.H.; Laird, J.R.; Ansel, G.M.; Shuck, J.W. Complex endovascular treatment for critical limb ischemia in poor surgical candidates: a pilot study. J. Endovasc. Ther., 2002, 9, 599-604.

[12] Prager, M.; Hoizenbein, T.; Aslim, E.; Domenig, C.h, Mulhbacher, F.; Kretschmer, G. Fresh arterial homograf transplantation: a novel concept for critical limb ischemia. Eur. J. Vasc. Endovasc. Surg., 2002, 24, 314-321.

[13] Novo, S. Management of the diseases of the arteries of the lower limbs. In Angiology in the Practice. Salmasi, A.M. and Strano, A, Eds, Kluwer Academic Press: Dordrecht, The Netherlands, 1996, pp. 307- 321 .

[14] Norgren, L. Pharmacotherapy for critical limb ischemia. Diabetes Metab. Res. Rev., 2000, 16 (Suppl. 1), S37-S41.

[15] The ICAI Study Group. Prostanoids in chronic critical leg ischemia: The results of a large randomized Trial with Prostaglandin E1. Ann. Intern. Med., 1999, 130, 412-21.

[16] Dawson, D.L.; Hagino, R.T. Critical Limb Ischemia. Curr. Treat. Options Cardiovasc. Med.; 2001, 3, 237-249.

[17] Shyu, K.G.; Chang, H.; Wang, B.W.; Kuan, P. Intramuscular vascular endothelial growth factor gene therapy in patients with chronic critical leg ischemia. Am. J. Med., 2003, 114, 85-92.

[18] Konstantinov, B.A.; Nechaenko, M.A.; Malinovskais, T.N.; Kulagina, T.I.; Minaev, V.V.; Tataian, M.V. Electrical stimulation of the spinal cord in cardiovascular disease. Vestn. Ross. Akad. Med. Nauk., 2002, 5, 17-23.

[19] Spincemaille, G.H.; de Vet, H.C.; Ubbink, D.T.; Jacobs, M.J. The results of spinal cord stimulation in critical limb ischemia: a review. Eur. J. Vasc. Endovasc. Surg., 2001, 21, 99-105.

[20] Tomlinson, L. Case study to illustrate a multidisciplinary approach to a case of critical limb ischemia and the role of chemical lumbar sympathectomy. J. Tissue Viabilità, 2000, 10, 140-143.

[21] Delis, K.; Husmann, M.; Nicolaides, A.; Wolfe, J.; Cheshire, N. Enhancing foot skin blood flow flux in peripheral vascular disease using intermittent pneumatic compression: controlled study on claudicants and grafted arteriopathies. World J. Surg., 2002, 26, 861-866.

[22] Kroese, A.J.; Strande, E. How critical is chronic critical leg ischaemia? Ann. Chir. Gynaecol., 1998, 87, 141-144.

[23] Fontaine, R.; Kim, M.; Kieny, R. Die chirurgische Behandlung der peripheren Durch-blutungsstorungen. Helvetia Chirurgica Acta, 1954, 5/6, 199-533.

[24] Second European Consensus Document on Chronic Critical Leg Ischemia. Circulation, 1991, 84 (Suppl.4), 1-26.

[25] The Vascular Surgical Society of Great Bretain and Ireland. Critical limb ischemia: management and outcome. Report of a National Survey. Eur. J. Vasc. Endovasc. Surg., 1995, 10, 108113.

[26] Matzke, S.; Lepantalo, M. Claudication does not always precede critical leg ischemia. Vasc. Med., 2001, 6, 77-80.

[27] Eickhoff, J.H.; Hansen, H.J.; Lorentzen, J.E. The effect of arterial reconstruction on lower limb amputation rate. An epidemiological survey based on reports from Danish hospitals. Acta. Chir. Scand. Suppl., 1980, 502, 181-187.

[28] Da Silva, A.; Widmer, L.K.; Ziegler, H.W.; Nissen, C.; Schweiger, W. The Basle longitudinal study; report on the relation of initial glucose level to baseline ECG abnormalities, peripheral artery disease, and subsequent mortality. J. Chorn. Dis., 1979, 32, 797-803.

[29] McGrath, M.A.; Graham, A.R.; Hill, D.A.; Lord, R.S.; Tracy, G.D. The natural history of chronic leg ischemia. World J. Surg., 1983, 7, 314-318.

[30] Taylor, L.M.; Hamre, D.; Dalman, R.L.; Porter, J.M. Limb salvage vs amputation for critical ischemia: the role of vascular surgery. Arch. Surg., 1991, 126, 1251-1258.

[31] Hickey, N.C.; Thomson, I.A.; Shearman, C.P.; Simms, M.H. Aggressive arterial reconstruction for critical lower limb ischaemia. Br. J. Surg., 1991, 78, 1476-1478.

[32] Norgren, L.; Alwmark, A.; Angqvist, K.A.; Hedberg, B.; Bergqvist, D.; Takolander, R.; Claes, G.; Lundell, A.; Holm, J.; Jivegard, L.; et al. A stable prostacyclin analogue (iloprost) in the treatment of ischaemic ulcers of the lower limb. A ScandinavianPolish placebo controlled, randomised multicenter studies. Eur. J. Vasc. Surg., 1990, 4, 463-637.

[33] Bliss, B.; Wilkins, D.; Campbell, W.B. Treatment of limb threatening ischaemia with intravenous Iloprost: a randomised double-blind placebo-controlled study. Eur. J. Vasc. Surg., 1997, $5,511-516$.
[34] Kugler, C.F.; Rudofsky, G. The challenges of treating peripheral arterial disease. Vasc. Med., 2003, 8, 109-14.

[35] Shigematsu, H. Endovascular procedures for peripheral arterial disease. Nippon Geka Gakkai Zasshi, 2003, 8, 562-6.

[36] Tunis, S.R.; Bass, E.B.; Steinberg, E.P. The use of angioplasty, bypass surgery, and amputation in the management of peripheral vascular disease. New Engl. J. Med., 1991, 325, 556-62.

[37] Karlstrom, L.; Bergqvist, D. Effects of vascular surgery on amputation rates and mortality. Eur. J. Vasc. Endovasc. Surg., 1997, 14, 273-283.

[38] Molloy, K.J.; Nasim, A.; London, N.J.; Naylor, A.R.; Bell, P.R.; Fishwick, G.; Bolia, A.; Thompson, M.M. Percutaneous translumnal angioplasty in the treatment of critical limb ischemia. J. Endovasc. Ther., 2003, 2, 298-303.

[39] Nasr, M.K.; McCarthy, R.J.; Hardman, J.; Chalmers, A.; Horrocks, M. The increasing role of percutaneus transluminal angioplasty in the primary management of critical limb ischaemia. Eur. J. Endovasc. Surg., 2002, 5, 398-403.

[40] Ebskov, L.B.; Schroeder, T.V.; Holstein, P.E. Epidemiology of leg amputation: the influence of vascular surgery. Br. J. Surg., 1994, 81, 1600-1603.

[41] Luther, M. The influence of arterial reconstructive surgery on the outcome of critical leg ischaemia. Eur. J. Vasc. Surg., 1994, 8, 682-689.

[42] Pell, J.P.; Fowkes, F.G.; Ruckley, C.V.; Clarke, J.; Kendrick, S.; Boyd, J.H. Declining incidence of amputation for arterial disease in Scotland. Eur. J. Vasc. Surg., 1994, 8, 602-606.

[43] Matzke, S.; Biancari, F.; Ihlberg, L.; Alback, A.; Kantonen, I.; Rallo, M.; Lepantalo, M. Increased preoperative C-reactive protein level as a prognostic factor for postoperative amputation after femoro-popliteal bypass surgery for CLI. Ann. Chir. Gynaecol., 2001, 90, 19-22.

[44] Wolfe, J.N. Defining the outcome of critical ischaemia: a one year prospective study. Br. J. Surg., 1986, 73, 321.

[45] Tripses, D.; Pollak, E.W. Risk factors in healing of below-knee amputation. Appraisal of 64 amputations in patients with vascular disease. Am. J. Surg., 1981, 141(6), 718-720.

[46] Burgess, E.M.; Matsen, F.A. 3rd, Wyss, C.R.; Simmons, C.W. Segmental transcutaneous measurements of PO2 in patients requiring below-the-knee amputation for peripheral vascular insufficiency. J. Bone Joint Surg. Am., 1982, 64(3), 378-382.

[47] Dormandy, J.; Belcher, G.; Broos, P.; Eikelboom, B.; Laszlo, G.; Konrad, P.; Moggi, L.; Mueller, U. Prospective study of 713 below-knee amputations for ischaemia and the effect of a prostacyclin analogue on healing. Hawaii Study Group. Br. J. Surg., 1994, 81(1), 33-37.

[48] Kihn, R.B.; Warren, R.; Beebe, G.W. The geriatric amputee. Ann. Surg., 1972, 176, 305-314.

[49] Loosemore, T.M.; Chalmers, T.C.; Dormandy, J.A. A metaanalysis of randomised placebo-controlled trials in Fontaine stages III and IV peripheral occlusive arterial disease. Int. Angiol., 1994, 13, 33-42.

[50] Banyay, S.; Jenelten, R.; Wagner, S.; Alimann, J.; Banyai, M.; Koppensteiner, R. Outpatient treatment of severe peripheral ischemia with intravenous intermittent low-dose Iloprost. An open pilot study. Int. Angiol., 2002, 21, 36-43.

[51] Belcaro, G.; Nicolaides, A.N.; Cipollone, G.; Laurora, G.; Incandela, L.; Cazaubon, M.; Barsotti, A.; Ledda, A.; Errichi, B.M.; Cornelli, U.; Dugall, M.; Corsi, M.; Mezzanotte, L.; Geroulakos, G.; Fisher, C.; Szendro, G.; Simeone, E.; Cesarone, M.R.; Nucci, M.; Agus, G.; De Sanctis.; M.T, Ricci, A.; Ippolito, E.; Vasdekis, S.; Cristopoulos, D.; Helmis, H. Normograms used to define the short-term treatment with PGE1 in patients with intermittent claudication and critical ischemia. The ORACLE (Occlusion Revascularization in the Atherosclerotic Critical Limb) Study Group. The European Study. Angiology, 2000, 51 (suppl. 8 part 2), S3-S13.

[52] Antiplatelet Trialists' Collaboration. Collaborative overview of randomised trials of antiplatelet theraphy. I: prevention of death, myocardial infarction, and stroke by prolonged antiplatelet theraphy in various categories of patients. $B M J, \mathbf{1 9 9 4}, 308,81$ 106.

[53] Antiplatelet Trialists' Collaboration. Collaborative overview of randomised trials of antiplatelet theraphy. II: maintenance of vascular graft or arterial patency by antiplatelet theraphy therapy. BMJ, 1994, 308, 159-168. 
[54] CAPRIE Steering Committee. A randomized, blinded, trial of clopidogrel versus aspirin in patients at risk of ischaemic events (CAPRIE). Lancet, 1996, 348, 1329-39.

[55] Palmer-Kazen, U.; Wahlberg, E. Arteriogenesis in peripheral arterial disease. Endothelium, 2003, 10, 225-32.

[56] Novo, S, Coppola, G. The Cardiovascular Risk Burden of Peripheral Arterial Disease (PAD). Invited Reports from the 17th International Congress on Thrombosis, Monduzzi Editore: Bologna - MEDIMOND Inc.; 2002, CX26R9044, 231-8

[57] Vogt, M.T.; Cauley, J.A.; Newman, A.B.; Kuller, L.H.; Hulley, S.B. Decreased ankle/arm blood pressure index and mortality in elderly women. JAMA, 1993, 270(4), 465-469.

[58] The I.C.A.I. Group (Gruppo di Studio dell'ischemia critica degli arti inferiori). Long-term mortality and its predictors in patients with critical limbs ischemia. Eur. J. Vasc. Surg., 1997, 14, 91-95.

[59] Schneider, E.; Gruntzig, A.; Bollinger, A. Die perkutane transluminale Angioplastie (PTA) in den Stadien III und IV der peripheren arteriellen Verschlusskrankheit. VASA, 1982, 11, 336339.
[60] Walker, S.R.; Yusuf, S.W.; Wenham, P.W.; Hopkinson, B.R. Renal complications following endovascular repair of abdominal aortic aneurysms. J. Endovasc. Surg., 1998, 5, 318-322.

[61] Pedrinelli, R.; Dell' Omo, G.; Barchielli, A.; Berchiolli, R.; Melillo, E.; Mariani, M.; Balbarini, A.; Ferrari, M. Fibrinogen and mortality in chronic critical limb ischemia. J. Intern. Med., 1999, $245,75-81$

[62] Collaborative meta-analysis of randomised trials of antiplatelet therapy for prevention of death, myocardial infarction, and stroke in high risk patients. Br. Med. J., 2002, 324, 71-86.

[63] MRC/BHF Heart Protection Study of cholesterol lowering with simvastatin in 20, 536 high-risk individuals: a randomised placebocontrolled trial. Lancet, 2002, 360, 7-22.

[64] The Heart Outcomes Prevention Evaluation Study Investigators. Effects of an angiotensin-converting-enzyme inhibitor, ramipril, on cardiovascular events in high-risk patients. N. Engl. J. Med., 2000, 342, 145-153. 